\title{
MASS TRANSFER STUDIES ON EXTERNAL LOOP AIRLIFT REACTOR
}

\author{
Naveen Prasad B.S. ${ }^{1}$, Velan. $\mathbf{M}^{2}$ \\ ${ }^{1}$ Department of Chemical Engineering, Sathyabama University, Chennai, India \\ ${ }^{2}$ Department of Chemical Engineering, Anna University, Chennai, India \\ Email : 'bsnaveenprasad@yahoo.com
}

\begin{abstract}
Experiments were conducted to investigate the influence of superficial gas velocity and fluid properties on the volumetric mass transfer coefficient in Newtonian and non-Newtonian systems in the riser and down comer of an external loop airlift reactor. Aqueous solutions of carboxy methyl cellulose, $\mathrm{CMC}$ was used as the non-Newtonian fluid. The $\mathrm{k}_{\mathrm{L}} \mathrm{a}$ increased with increase in $\mathrm{U}_{\mathrm{sg}}$ and of alcohol concentrations and a decreasing trend was observed with increase in concentration of CMC for twophase system. The proposed correlations predicted the experimental data well.
\end{abstract}

KEYWORDS: External loop airlift reactor, riser, three-phase, gas holdup, mass transfer coefficient and non-Newtonian fluid.

\section{INTRODUCTION}

Airlift reactors are widely used in various industrial applications such as aerobic fermentations and biological treatment of wastewater due to its simple design, good mixing characteristics and low power requirements. In an external loop airlift reactor the riser and down comer are separate tubes connected at the top and bottom and the zone in which gas is sparged is known as the riser (Chisti and Moo-Young, 1987, Wang et al (2003), Ruen-ngam et al (2008)).

A three-phase airlift reactor offers considerable advantages over traditional three phase contactors such as bubble columns and fluidized beds. This includes a lowering of the gas requirement of complete suspension of the solids, elimination of stagnant zones, rapid mixing and the absence of the need for external circulation systems of which are desirable in range industrial processes. The hydrodynamic behavior in internal loop and multiphase mass transport in external loops have been studied by Livingston and Zhang (1993). The gas-liquid mass transfer characteristics of the ALC in forms of mass transfer coefficient and specific interfacial area. It was found that the specific interfacial area, rather than the mass transfer coefficient, played a more significant role in controlling the overall rate of mass transfer in the system examined by Wongsuchoto et al (2003) Quijano et al (2009). This present paper discusses experimental results on mass transfer coefficient in the riser of an external loop airlift reactor.

\section{EXPERIMENTAL SETUP}

The schematic diagram of the experimental set-up is shown in Figure 1. The reactor was constructed of acrylic of inner diameter $0.084 \mathrm{~m}$ and $2.6 \mathrm{~m}$ in height. The riser and down comer are connected with an inclined angle $45^{\circ}$ at the top and bottom section of the reactor. Perforated plate gas sparger with 243 holes of $1 \mathrm{~mm}$ diameter on a triangular pitch was fixed at the base of the reactor and air from the compressor was passed to the reactor through an air filter, pressure regulator and calibrated rotameter.

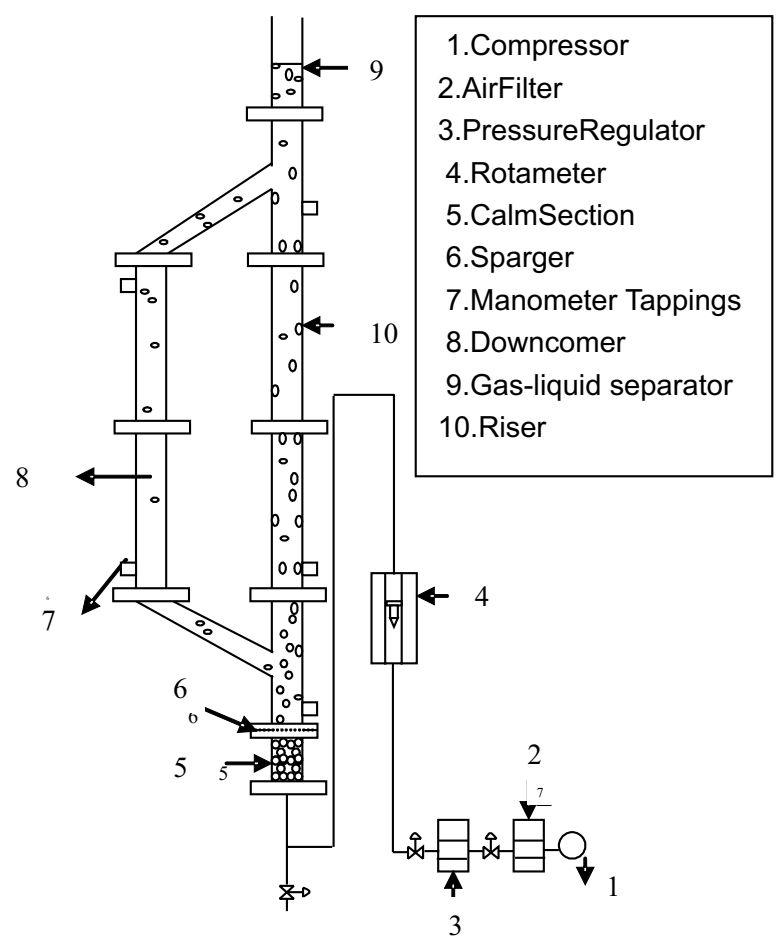

Fig.1 Experimental setup of External Loop Airlift Reactor

\section{MATERIALS AND METHODS}

The rate of oxygen transfer is related to the overall volumetric mass transfer coefficient and the concentration driving force by the equation (ideal mixing of liquid phase in the reactor assumed).

$$
d C_{L} / d t=k_{L} a\left(C^{*}-C_{L}\right)
$$


where $C_{L}$ and $C^{*}$ are instantaneous and the saturation (or equilibrium) concentration respectively of the dissolved oxygen in the liquid. For steady hydrodynamic and physico-chemical conditions the $\mathrm{k}_{\mathrm{L}} \mathrm{a}$ is a time-variant, integration of equation 3.8 between the time limits $C_{L}=C_{L O}$ at $t=0$ and $C_{L}=C_{L}$ at $t=t$, yields

$$
\ln \left(C^{*}-C_{L O}\right) /\left(C^{*}-C_{L}\right)=k_{L} a t
$$

The coefficient $k_{L}$ a was obtained from the plot of $\ln \left(C^{*}\right.$ $\left.C_{L O}\right) /\left(C^{*}-C_{L}\right)$ versus $t$. The volumetric mass transfer coefficient values were also obtained at room temperature for three-phase systems using the same procedure.

The dissolved oxygen probe was mounted in the external loop airlift reactor. The column was purged with nitrogen until the level of oxygen dropped to almost zero before air could be introduced into the column. This was done for every flow rate of air used. The time-change in dissolved oxygen (DO) in the reactor was monitored continuously from the instant at which the airflow began using dissolved oxygen meter (Oximeter OXI 191). The response time of the probe $E$ was found to be less than 10 sec. Since the condition $k_{L} a<1 / E$ was fulfilled, the electrode dynamics was neglected in the calculation and the $k_{\llcorner} a$ value for each run was obtained from the slope of the straight line in the plot $\ln \left(C^{*}\right.$ -

$\left.C_{L} 0\right) /\left(C^{*}-C_{L}\right)$ versus $t$ where $C_{L}$ and $C^{*}$ are the instantaneous and the saturation concentrations, respectively, of the dissolved oxygen in the liquid (Dunn and Einsele 1975).

\section{A. Measurement of physical properties of particles}

The diameters of various solid particles were found using the average diameter obtained from weight cumulative particle size distribution method. The densities were measured by weighing a known number of particles. The density was determined as the ratio of mass to volume and the values are given in Table 1.

Table 1. Properties of solid particles

\begin{tabular}{|l|c|c|}
\hline Particle & $\begin{array}{c}\text { Diameter, } \\
\mathbf{d}_{\mathbf{p}}(\mathrm{m})\end{array}$ & $\begin{array}{c}\text { Density, } \\
\boldsymbol{\rho}_{\mathbf{s}}\left(\mathbf{k g} / \mathrm{m}^{3}\right)\end{array}$ \\
\hline Polystyrene & 0.0036 & 1025.55 \\
\hline Nylon-6 & 0.0035 & 1084.24 \\
\hline
\end{tabular}

\section{B. Measurement of properties of liquids}

The viscosity of different concentrations of aqueous glycerol was determined using Ostwald's viscometer and surface tension was determined by drop weight method at room temperature $(252 \mathrm{C})$ and the values are given in Table 2.

Table 2. Physical properties of aqueous solutions of glycerol

\begin{tabular}{|r|r|r|r|}
\hline $\begin{array}{r}\text { Concentration } \\
\text { of glycerol (v/v) }\end{array}$ & $\begin{array}{r}\text { Density, } \\
\rho_{1}\left(\mathrm{~kg} / \mathrm{m}^{3}\right)\end{array}$ & $\begin{array}{r}\text { Viscosity, } \\
\mu l(\mathrm{mPa} . \mathrm{s})\end{array}$ & $\begin{array}{r}\text { Surface tension, } \\
\sigma_{l}(\mathrm{~N} / \mathrm{m})\end{array}$ \\
\hline $30 \%$ & 1056 & 1.94 & 0.0704 \\
\hline $40 \%$ & 1088 & 2.56 & 0.0675 \\
\hline $50 \%$ & 1107 & 3.74 & 0.0669 \\
\hline
\end{tabular}

The viscosity, surface tension of isoamyl alcohol and propanol were determined by drop weight method at room temperature (252C) and the values are given in Table 3.

The rheological properties of different concentration of aqueous solutions of CMC were measured using a concentric viscometer (Haake). The flow behavior of CMC is described by the power law model and the effective viscosity was calculated using equation proposed by Nishikawa et al 1977.

$\eta_{\text {eff }}=K \gamma^{n-1}$

$\gamma=5000 U_{s g r}$

where $\mathrm{K}$ and $\mathrm{n}$ are the flow consistency index and flow index respectively. The deviation of the flow index $n$, indicates the degree of deviation from Newtonian flow behavior. The physical and rheological properties are listed in the Table 4.

Table 3. Physical properties of aqueous solutions of isoamyl alcohol and propanol

\begin{tabular}{|l|c|c|c|c|}
\hline \multicolumn{1}{|c|}{ Additive } & Concentrations & $\begin{array}{c}\text { Density, } \\
\rho_{l}\left(\mathbf{k g} / \mathrm{m}^{3}\right)\end{array}$ & $\begin{array}{c}\text { Viscosity, } \\
\mu_{l}(\mathrm{mPa} . \mathbf{s})\end{array}$ & $\begin{array}{c}\text { Surface } \\
\text { tension, } \\
\sigma_{l}(\mathrm{~N} / \mathrm{m})\end{array}$ \\
\hline Isoamyl alcohol & $20 \mathrm{mg} / \mathrm{l}$ & 998 & 1.0 & 0.072 \\
\hline Isoamyl alcohol & $40 \mathrm{mg} / \mathrm{l}$ & 998 & 1.0 & 0.071 \\
\hline Isoamyl alcohol & $60 \mathrm{mg} / \mathrm{l}$ & 998 & 0.98 & 0.069 \\
\hline Isoamyl alcohol & $80 \mathrm{mg} / \mathrm{l}$ & 998 & 0.97 & 0.069 \\
\hline Isoamyl alcohol & $100 \mathrm{mg} / \mathrm{l}$ & 997 & 0.97 & 0.067 \\
\hline Propanol & $0.1 \mathrm{wt} \%$ & 998 & 1.0 & 0.072 \\
\hline Propanol & $0.2 \mathrm{wt} \%$ & 998 & 1.0 & 0.072 \\
\hline Propanol & $0.3 \mathrm{wt} \%$ & 998 & 0.98 & 0.070 \\
\hline Propanol & $0.4 \mathrm{wt} \%$ & 998 & 0.97 & 0.069 \\
\hline Propanol & $0.5 \mathrm{wt} \%$ & 998 & 0.97 & 0.068 \\
\hline
\end{tabular}


Table 4. Physical properties of aqueous solutions of $\mathrm{CMC}$

\begin{tabular}{|c|c|c|c|c|}
\hline $\begin{array}{c}\text { CMC } \\
\text { (wt. \% } \\
\text { in } \\
\text { water) }\end{array}$ & $\begin{array}{c}\text { Density, } \\
\rho l \\
(\mathrm{~kg} / \mathrm{m} 3)\end{array}$ & $\begin{array}{c}\text { Flow } \\
\text { consistency } \\
\text { index K } \\
(\mathrm{mPasn})\end{array}$ & $\begin{array}{c}\text { Flow } \\
\text { index } \\
\mathrm{n}\end{array}$ & $\begin{array}{c}\text { Surface } \\
\text { tension, } \\
\sigma \\
(\mathrm{N} / \mathrm{m})\end{array}$ \\
\hline 0.1 & 999 & 10 & 0.88 & 0.0720 \\
\hline 0.2 & 1000 & 34 & 0.80 & 0.0716 \\
\hline 0.3 & 1000 & 41 & 0.66 & 0.0712 \\
\hline
\end{tabular}

\section{RESULTS AND DISCUSSION}

A. Effect of volumetric mass transfer coefficient $\left(k_{L} a\right)$ with superficial gas velocity for air-alcohol systems

The variation of volumetric mass transfer coefficient, $\mathrm{k}_{\mathrm{L}} \mathrm{a}$ with superficial gas velocity for air-alcohol systems is shown in Figures $2 \mathrm{a}$ and $2 \mathrm{~b}$. It was observed that the kLa decreased with increase in the alcohol concentration and the observed values was found to be lower than that of airwater system. The addition of alcohol surfactant to water caused a reduction in $k_{\llcorner} a$ values over entire ranges of superficial gas velocities. This may be due to the tendency of surfactants to accumulate at the bubble surface and the created surface tension gradients caused tangential stress along the bubble surface and also decreased in bubble surface due to hindered internal circulation within the bubble. The observed trend agreed well with those reported in the literature (Al-Masry and Dukkan (1997) and Vasconcelos et al (2003) Yazdian etal (2009)).

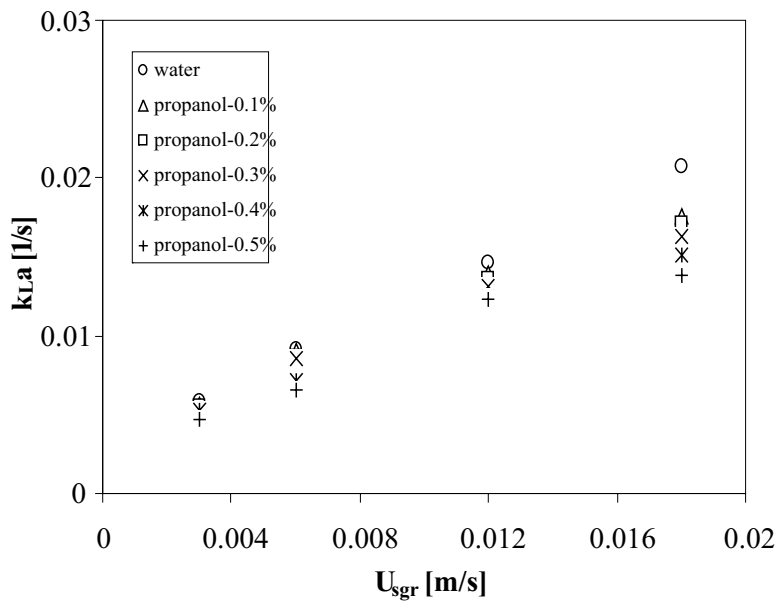

Fig. 2a Variation of $k_{\llcorner} a$ with superficial gas velocity for air-propanol system

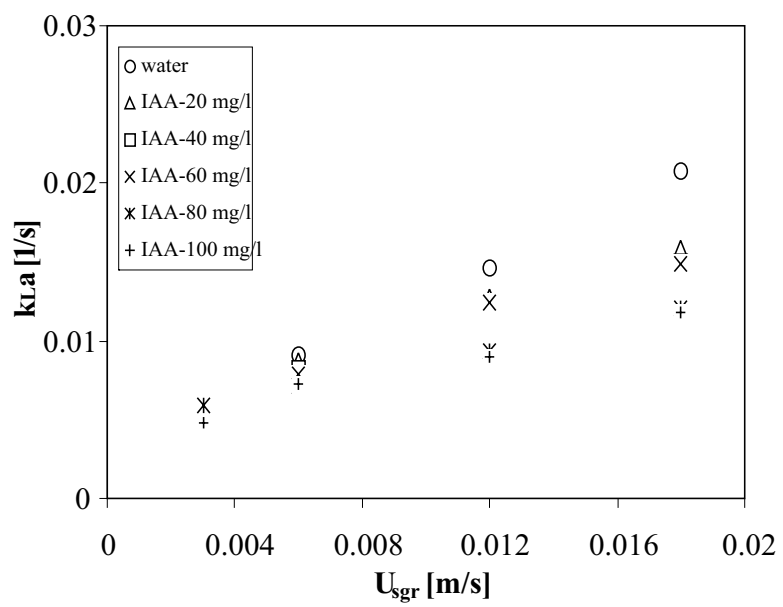

Fig. 2b Variation of $k$ La with superficial gas velocity for air-IAA system

B. Effect of volumetric mass transfer coefficient ( $k L a)$ with superficial gas velocity for air-glycerol system

The variation of volumetric mass transfer coefficient, $k_{L} a$ with superficial gas velocity for air-glycerol system is shown in Figure 3. It was observed that the $\mathrm{k}_{\mathrm{L}} \mathrm{a}$ increased with increase in superficial gas velocity in the riser and decreased with increase in the glycerol concentration. This may be due to the increase in liquid viscosity, which reduced the interfacial area available for mass transfer. The observed $k_{\llcorner}$a value was found to be lower than that of air-water system.

C.Effect of volumetric mass transfer coefficient ( $k L a)$ with superficial gas velocity for air-CMC system

The variation of volumetric mass transfer coefficient, $\mathrm{k}_{\mathrm{L}} \mathrm{a}$ with superficial gas velocity for air-CMC system is shown in Figure 4. It was observed that the $\mathrm{k}_{\llcorner} \mathrm{a}$ increased with increase in superficial gas velocity in the riser

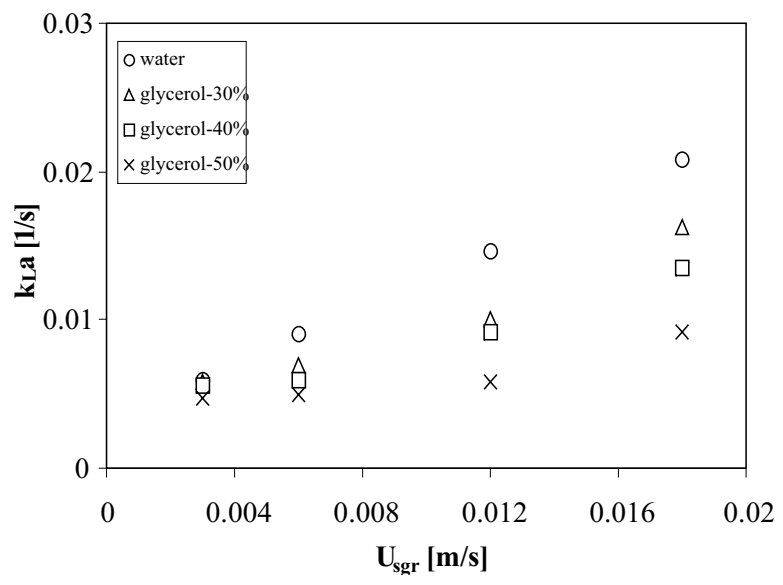

Fig. 3. Variation of $k_{L} a$ with superficial gas velocity for air-glycerol system 
and decreased with increasing $\mathrm{CMC}$ concentration. This may be due to increase in viscosity of liquid phase.

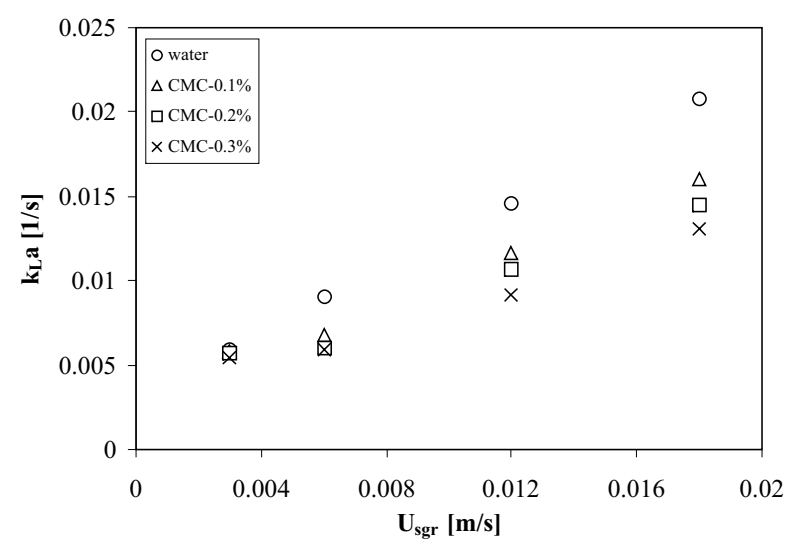

Fig. 4 Variation of $k_{\llcorner} a$ with superficial gas velocity for air-CMC system

\section{Empirical correlation}

The value of volumetric mass transfer coefficient, $\mathrm{k}_{\mathrm{L}} \mathrm{a}$ for two-phase system have been well correlated in terms of operating variables as

\section{Newtonian System}

\section{Air-water system}

$k_{\mathrm{L}} a=0.204 U_{\text {sgr }}^{0.782} \mu^{-0.0595} \mathrm{R}^{2}=0.8$

Parity plots between experimental and predicted values of $\mathrm{k}_{\mathrm{L}} \mathrm{a}$ based on the proposed empirical equation 5 for air-water system is shown in Figure 5. The average RMS error for $k_{\llcorner} a$ is $17 \%$. It was found that the proposed equation fitted the experimental data well within $35 \%$.

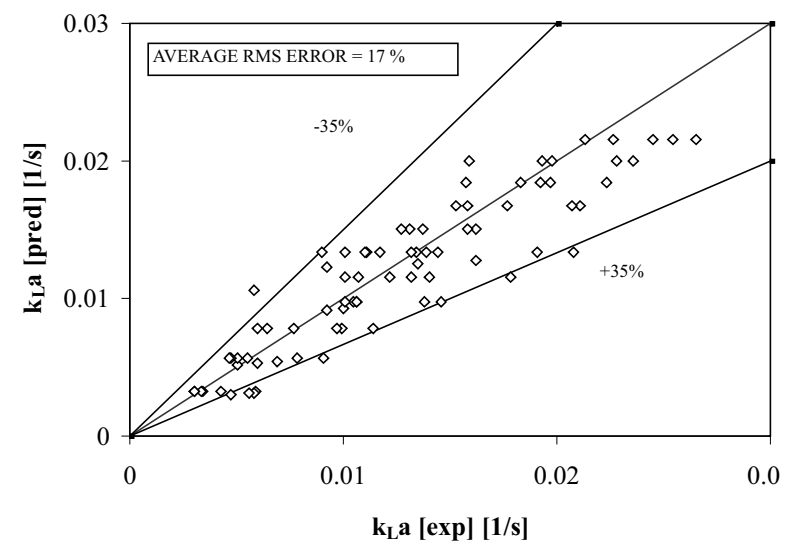

Fig. 5 Parity diagram for $k_{\llcorner} a$ estimated from empirical Equation 5 for air-water system

\section{Air-alcohols-solid system}

The value of volumetric mass transfer coefficient, $\mathrm{k}_{\mathrm{L}} \mathrm{a}$ for two and three-phase system have been well correlated in terms of operating variables as

$$
k_{\mathrm{L}} a=\mathrm{R}^{0}=115 U_{\mathrm{sgr}}^{0.607} \sigma^{-0.065} 0.9
$$

Parity plots between experimental and predicted values of kLa based on the proposed empirical equation 6 for air-alcohol system is shown in Figure 6. The average RMS error for $k_{L} a$ is $17 \%$. It was found that the proposed equation fitted the experimental data well within $25 \%$.

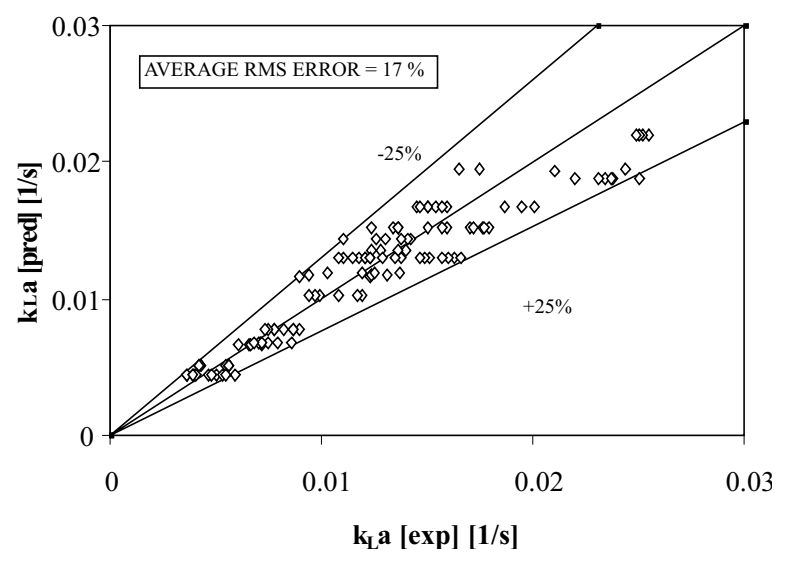

Fig. 6 Parity diagram for $k_{\llcorner} a$ estimated from empirical Equation 6 for air-alcohol system

\section{Air-CMC-solids system}

The value of volumetric mass transfer coefficient for two and three-phase system have been well correlated in terms of operating variables as

$$
k_{\mathrm{L}} a=0.0587 U_{\mathrm{sgr}}^{0.499} \eta_{\text {eff }}^{-0.079} \mathrm{R}^{2}=0.88
$$

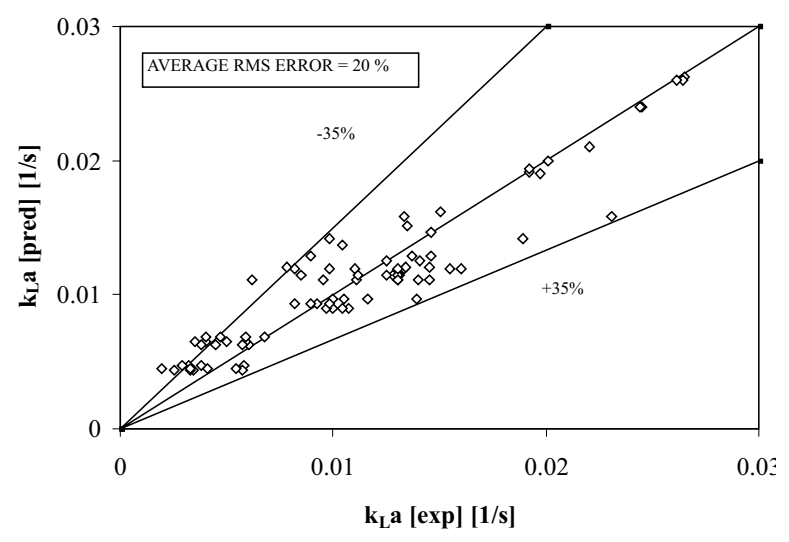

Fig. 7 Parity diagram for $k_{\llcorner} a$ estimated from empirical Equation 4.15 for air-CMC-solids system 
Parity plots between experimental and predicted values of $k_{L} a$ based on the proposed empirical equation 7 for air-CMC-solids system is shown in Figure 7. The average RMS error for $k_{L} a$ is $20 \%$. It was found that the proposed equation fitted the experimental data well within $35 \%$.

\section{CONCLUSION}

The volumetric mass transfer coefficient is calculated from oxygen uptake rate using dynamic method. The volumetric mass transfer coefficient increased with an increase in the superficial gas velocity and decreased with increase in concentrations of liquid medium used. The proposed correlation for volumetric mass transfer coefficient predicted the experimental data well for both Newtonian and non-Newtonian systems.

\section{List of Symbols}

Usg Superficial gas velocity in the riser $(\mathrm{m} / \mathrm{s})$

$\mathrm{K}$ Consistency index in a power law model(mPa-s)

n Flowindex in a power law model

$\mathrm{k}_{\mathrm{L}} \mathrm{a} \quad$ Volumetric mass transfer coefficient $(1 / \mathrm{s})$

S Solid

Liquid

g Gas

Riser

d Downcomer

\section{Greek symbols}

$\sigma \quad$ Surface tension $(\mathrm{mNm}-1)$

$\mu \quad$ Viscosity (mPas)

$\eta \quad$ Effective viscosity (mPas)

$\rho \quad$ Density $(\mathrm{kg} / \mathrm{m} 3)$

\section{REFERENCES}

[1] Chisti,M.Y and M.Moo-Young,(1987) Chem.Eng. Commun,60,195-242.

[2] Wang S., Arimatsu Y., Koumatsu K., Furumoto K., Yashimoto M., Fukunaga K. and Nakao K. (2003), Chem. Eng. Sci., 58, 3353-3360.

[3] Ruen-ngam.D, Wongsuchoto.P, Limpanuphap.A, Charinpanitkul .T, and Pavasant. P, (2008), Chem. Eng. J., 141, 222-232.

[4] Livingston, A., and S.F.Zhang, (1993) Chem.Eng.Sci.,48,1641-1654

[5] Wongsuchoto.P, Charinpanitkul.T, Pavasant.P, (2003), Chem. Eng. J., 92, 81-90.

[6] Quijano.G, Revah.S, Gutiérrez-Rojas.M, Luis B. FC, Thalasso.F, (2009), Process Biochemistry, 44, 619-624.

[7] Dunn I.J. and Einsele A, J. Appl. Chem. (1975), Biotechnol., 25pp. 707-720.

[8] Nishikawa M, Kato H. and Hasimoto K. (1977), Ind. Eng. Chem. Proc. Des. Devel., 16 133-137.

[9] Al-Masry W.A. and Dukkan A.R. (1997), Chem. Eng. J., 65, 263-271.

[10] Vasconcelos J.M.T., Rodrigue J M L., Ho C.S., Alves S.S. and Mendes R.L. (2003), Chem. Eng. Sci., Vol.58,pp. 1431-1440.

[11] F. Yazdian, S.A. Shojaosadati, M. Nosrati, M. Pesaran Hajiabbas, and E. VasheghaniFarahani,(2009), Chem.Eng.Sci., 64, 2455-2465.

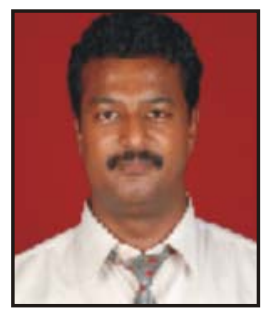

Mr. B.S. Naveen Prasad is presently working as a Lecturer, Department of Chemical Engineering, Sathyabama University, Chennai. He is doing his research at Sathyabama University and has publications in 4 international journals. 